\title{
Role of Maamora Nuclear Research Center to Develop Knowledge and Skills in Nuclear Applications
}

\author{
Taïb Marfak ${ }^{*}$, Houda Krafes \\ National Center for Energy, Nuclear Science and Technology, Morocco
}

Copyright $\bigcirc 2017$ by authors, all rights reserved. Authors agree that this article remains permanently open access under the terms of the Creative Commons Attribution License 4.0 International License

\begin{abstract}
Operated by CNESTEN, the Maamora Nuclear Research Center MNRC includes a 2 MW nuclear reactor and a dozen of specialized nuclear techniques laboratories dedicated to earth sciences, human health, industry, safety and security, radioactive waste management, etc. According to the CNESTEN overall vision and its strategic objectives, modern human resources tools were established such as: competencies repository, systematic approach for training SAT, multi-annual training program, evaluation system, etc. This paper presents all the HR projects identified and developed targeting the CNESTEN scientific and technical staff. The objective is to sustain the CNESTEN activities by qualifying its human resources, developing knowledge and expertise at both the individual and collective levels [1].
\end{abstract}

Keywords CNESTEN, MNRC, KM 'Knowledge Management', IAEA

\section{Introduction}

Since its creation in 1986, CNESTEN is engaged in promoting and developing nuclear science and technology in different socioeconomic sectors where the atom can provide a solution to the problems encountered.

With this regards, several programs of nuclear techniques applications covering the areas of health, water, environment, agriculture, industry, safety and security have been implemented at MNRC involving the end users and stakeholders.

During these last decades, CNESTEN invested in the development of its human capability through recruitment of young engineers, searchers, and technicians who were trained in nuclear science and technology in connection with the IAEA and in some similar centers in France, United States of America, Belgium, South-Africa and other countries.

This workforce contributed to the realization of the
Maamora Nuclear Research Centre MNRC, operated since 2003 , including a research reactor of $2 \mathrm{MW}$ power and a dozen laboratories dedicated to sectorial applications of nuclear techniques. The NRC is located at $25 \mathrm{~km}$ in the north of Rabat.

Started with a dozen of persons in the end of 1986, the CNESTEN staff was stabilized during the last years around 260 persons (fig. $n^{\circ} 1$ ).

The stagnation of CNESTEN staff is due to departure mostly for retirement (10 persons per year), and the limited number of new jobs (8 persons per year). In this context, CNESTEN is faced to enhance the staff performance in order to continue the development of its programs in terms of scientific production and commercial.

\section{Development and Transfer KM CNESTEN's Strategy}

The CNESTEN staff is characterized as follows: Average age is 42 years, Average seniority is 14 years, and females represent $30 \%$ while researchers, engineers and technicians staff represents more than $72 \%$. Twenty engineers and researchers have developed an international expertise and competence used by the IAEA in the context of sharing nuclear knowledge in Africa. The senior staff plays an important role in knowledge transfer within the CNESTEN generations and also at national and international level.

According to its missions leading with the promotion and development of knowledge and expertise in the field of nuclear applications at the national level, CNESTEN established with several universities partnership concerning creation of joint research units dedicated to nutrition and the management of radioactive waste.

CNESTEN is also involved in the academic training in several masters on the nuclear technology and engineering, nuclear safety and medical physics. In this framework, more than 130 students are received annually in training at the MNRC including $30 \mathrm{PhDs}$ degree.

All these actions are completed on behalf of the agreement 
that with the national universities and educational system.

The effort of dissemination of nuclear information is also done towards educational system, more than 1,500 students and scholars are received at the MNRC each year for visiting where explanations about the nuclear sciences and technology are given to them.

In cooperation with the IAEA, CNESTEN is actively contributing to the development of knowledge in the field of nuclear applications as a designated center in the fields of isotope hydrology, radiation protection, nuclear security, nondestructive testing and nutrition.

These training programs are supported by the IAEA and also some African countries that pay for their trainees.

\subsection{CNESTEN KM Challenges}

In its 2020 vision, CNESTEN has the ambition to further align its plans according to the national priorities in terms of climate changes, innovative research and national capacity building for nuclear and radiological safety and security.

In this framework, CNESTEN is looking for strengthening its regional role in Africa through research, training and expertise in nuclear science and technology.

However, these challenges combined with the stagnation of the CNESTEN workforce, imposed by the general context, are forcing further maintenance and development of the human and knowledge capital.

\subsection{CNESTEN KM Strategy and Actions}

Being the unique NRC in Morocco, CNESTEN has a specificity to manage specialized and rare expertise whose replacement cost, in case of departure, is very high in terms of delays or loss of expertise.

In this way, CNESTEN established, in 2013, a strategy to implement talent and expertise management in order to maintain a high level of performance at national and international level especially in terms of research programs, training and expertise.

\subsubsection{Organization}

In this strategy, a new organization has been set up based on four pillars respectively dedicated to the research studies, the optimization of nuclear facilities, the nuclear safety aspects and the support activities. Autonomy is encouraged in parallel to the audit and control which are also strengthened [2].

Under the general direction supervision, three directorates dedicated to core competencies activities such as research and development, nuclear safety and reactor utilizations are employing respectively 80,50 and 40 engineers and technicians. The support staff is 60 people.

\subsubsection{Repository of Jobs and Skills}

Furthermore, a repository of jobs and skills was established which allowed the CNESTEN to:

- have a better visibility of employment and its evolution,
- be provided with a performance assessment tool adapted to its specific activities,

- $\quad$ optimize organizational adjustments, enjoying a tool of decision support in recruitment, promotion, training and internal mobility, control staffing, jobs and skills;

- And prepare for the implementation of a proactive management system especially according to the identification of new jobs, qualification and skills (nuclear energy power, fuel cycle, material sciences, computing,...).

Height professional families or groups of activities were identified. They concern respectively Research activities, Reactor operating and utilization, Radioisotopes Production, Radioactive waste management, Technical Support, Strategic Planning, Marketing, Commercial, Cooperation and Communication

All these professional families are divided on 32 Jobs which include 102 job positions with specific description and requirement.

\subsubsection{Systematic Approach for Training}

In 2013, CNESTEN performed a Systematic Approach for Training SAT [3-4] which lead to the identification of training needs in core business, support, quality, management and personal development (Table $\mathrm{n}^{\circ} 1$ ).

Table 1. Distribution of the identified training needs

\begin{tabular}{|c|c|}
\hline Identified training needs & Percentage \\
\hline Core business & $46 \%$ \\
\hline Support & $6 \%$ \\
\hline Quality & $19 \%$ \\
\hline Management and personal development & $29 \%$ \\
\hline
\end{tabular}

The global training needs were estimated to 1200 Day-Man per year and concerning more than 120 persons. The total duration was evaluated to 220 weeks each year. The annual estimated cost is 2 Million Dirhams (Equivalent to 200000 Euros).

Regarding these needs [5], we have executed in 2014 and 2015 training plans focused on the quality management system (ISO 9001 and ISO 17025), good manufacturing practices for radiopharmaceuticals, management by objectives and projects, communication skills, leadership, business plan, sales force, coaching and public procurement. These initiatives concerned more than one hundred employees and covered an average of over 400 man-days. The support training actions represents $47 \%$ of the global annual training program.

Training actions focused on core business are generally carried out under the cooperation of CNESTEN with the IAEA and some of its counterparts in Europe, America and Asia. Thus, over five hundred days of training were conducted by forty employees each year.

The core business training concern Nuclear Safety \& Security, Facility Management, Statistics and Mathematics, Chemical Analysis, Radiometric Analysis, Material Sciences, 
Nuclear Instrumentation, Non Destructive Testing NDT, Radioimmunoassay RIA and radioactive waste management.

\subsubsection{HR Information System}

To manage the data capturing the new skills acquisition through training and their impact on raising individual and collective performance, CNESTEN is deploying an information system that enables it to monitor, evaluate and replace its human resources in alignment with new projects and requests from its national and international environments.

\subsubsection{Other Projects}

In addition, other projects are initiated and concern the establishment of a proactive HR management system dedicated to identify jobs and skills also the evaluation individual and collective performance.

\section{CNESTEN National and Regional 'Africa' Contribution to KM Transfer}

In relation with the component of its environment,
CNESTEN established several relation partnership and conventions with the universities, educational system and professional.

The communication and training programs deployed concern each year more than 1500 scholars and 140 students (more than $60 \%$ are preparing $\mathrm{PhD}$, engineer diplomas and masters in various fields). In 2015, the total duration student training reached 420 months.

The main training areas are concerning the bio-medical research, nutrition, radiopharmaceuticals production, water \& Climate, Environment \& natural resources, Material Sciences, Nuclear Instrumentation, NDT, Reactor technology and nuclear security.

Concerning the professional training, CNESTEN receives each year some 230 persons for 52 weeks global duration (62 \% for nuclear security, $24 \%$ for NDT and $14 \%$ for radiation protection training).

At the regional level and on behalf the cooperation with the IAEA, CNESTEN developed a training program towards African countries. As shown in figures 2 and 3, the number of trainers reached in 2016 fifty persons and duration cumulated at 600 weeks.

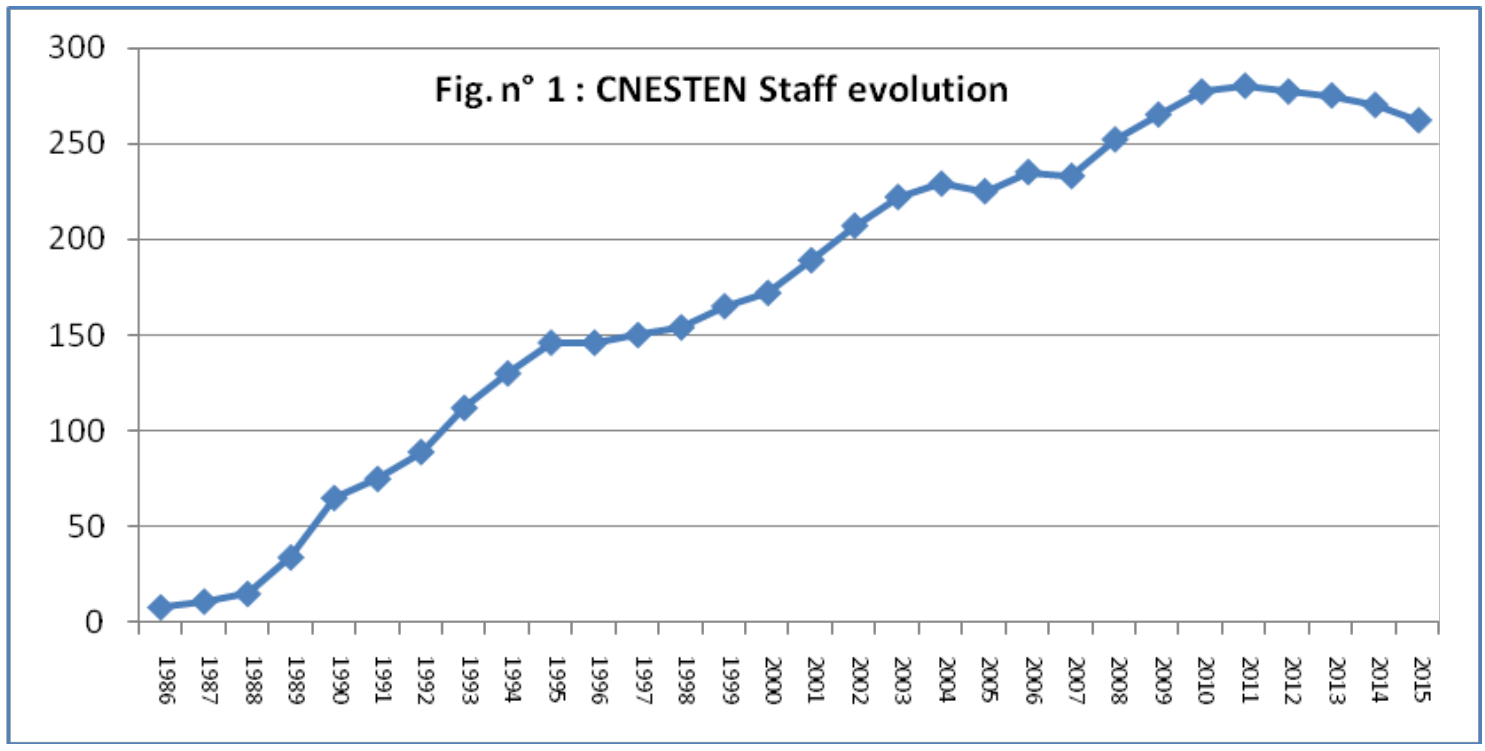

Figure 1. CNESTEN staff evolution 


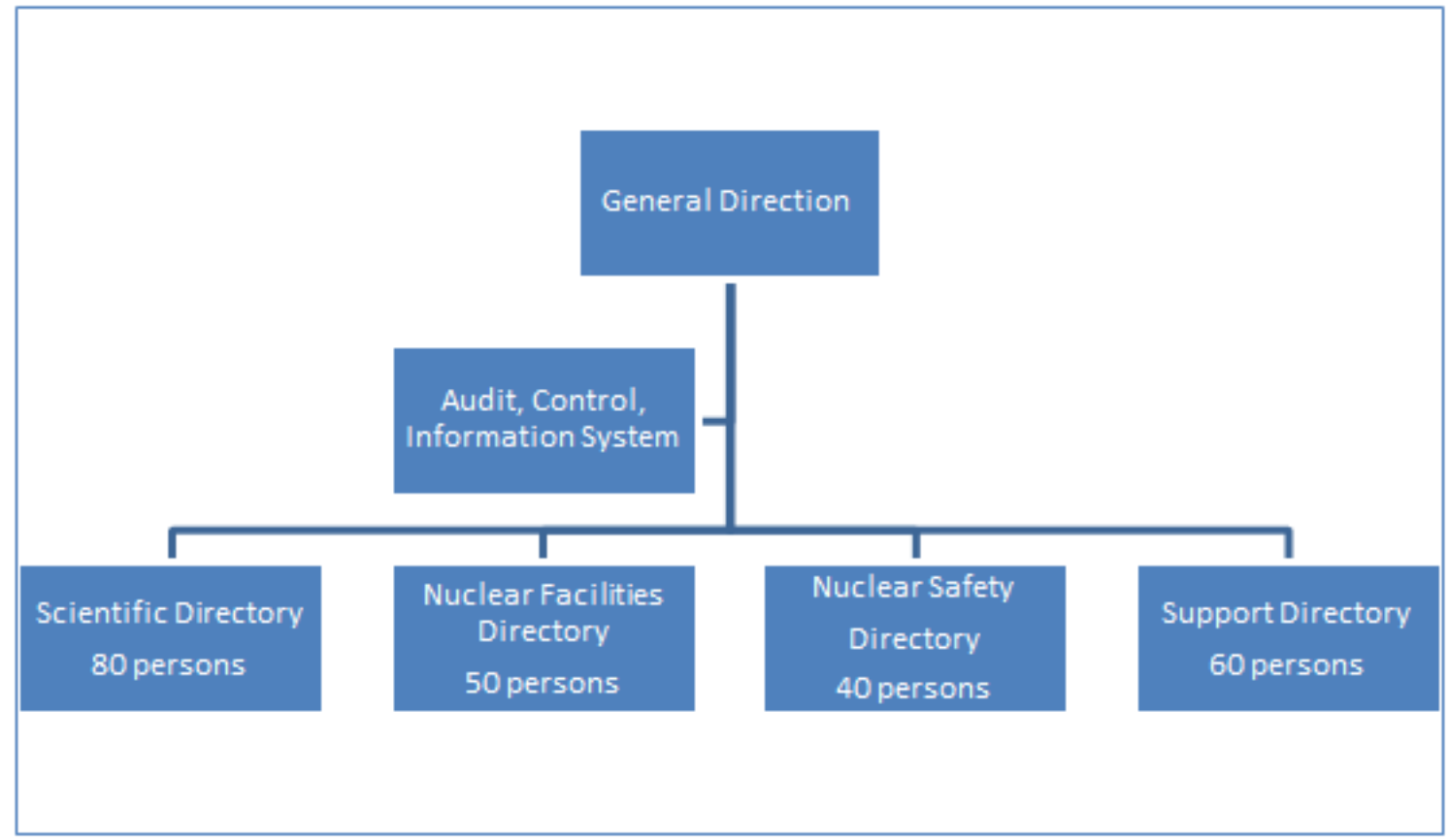

Figure 2. CNESTEN organization

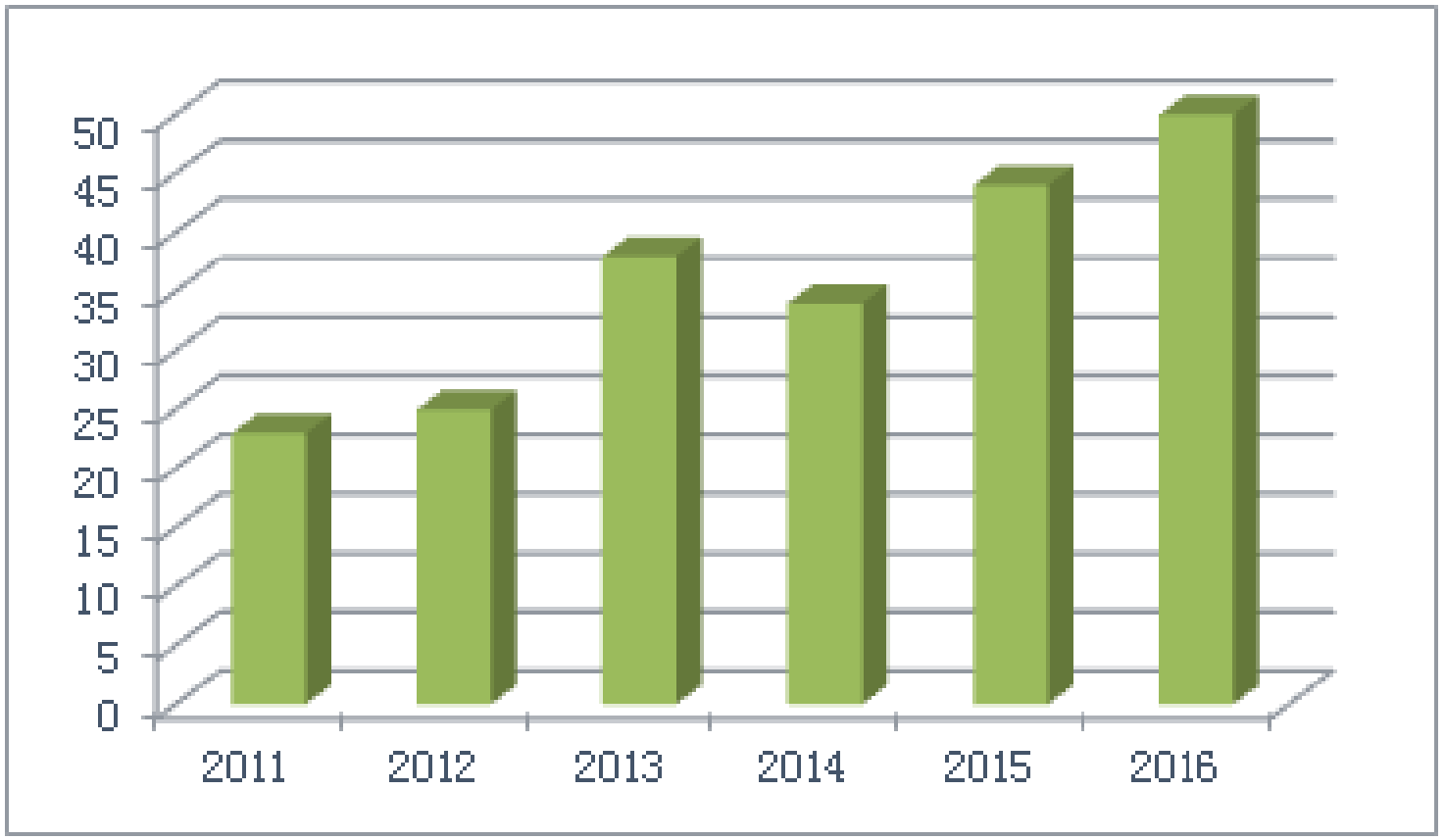

Figure 3. Number of African trainees 


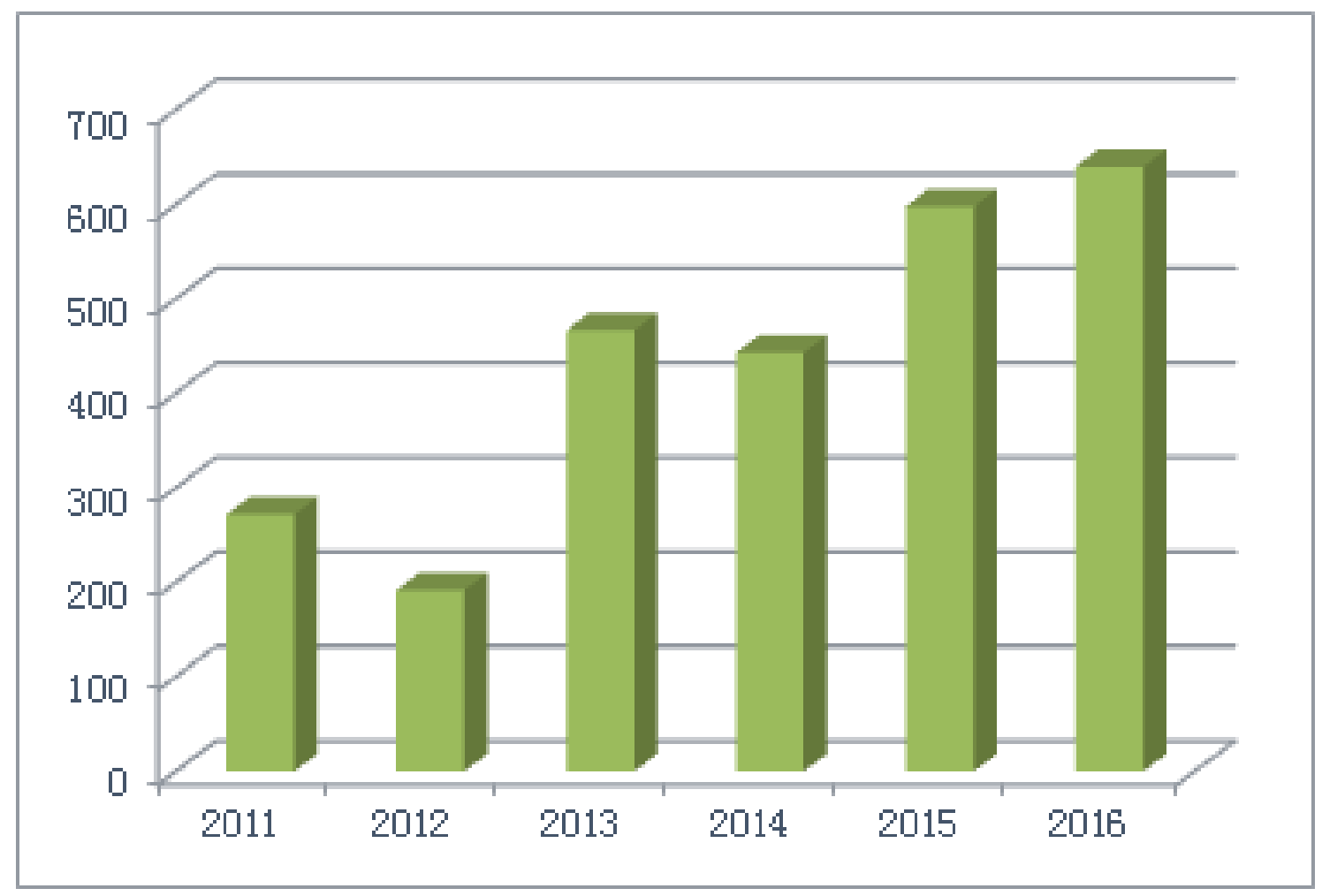

Figure 4. Duration in weeks/year

The main training areas are concerning the NDT, water \& climate, radiation protection, environment \& natural resources, material sciences, nuclear instrumentation, reactor technology, nuclear security and emergency situation.

Regarding all these training and education activities and programs, CNESTEN started the construction of a training center specialized in nuclear sciences and technology. This center, which will start in the end of 2017, will lead with internal needs, national and also regional.

\section{Conclusions}

Through this paper, we showed the interest to develop human resources management activities which prerequisites to build a comprehensive system of knowledge and expertise management.

In fact, this system is required to perform CNESTEN national and international positioning and is integrated in its global strategy and vision.

Furthermore, CNESTEN is playing a major role in the transfer of nuclear techniques applications knowledge to several African countries.

This experience could be shared with other institutions in Morocco and IAEA Member States in Africa and Middle East countries.

\section{Glossary}

1) CNESTE: Centre National de l'Energie, des Sciences et des Techniques Nucléaires

2) IAEA: International Atomic Energy Agency

3) MNRC: Maamora Nuclear Research Center

4) NRC: Nuclear Research Center

5) SAT: Systematic Approach for Training

\section{REFERENCES}

[1] IAEA Nuclear Energy Series, No. NG-T-6.10, Knowledge Management and Its Implementation in Nuclear Organizations, IAEA, Vienne/Austria April 2016

[2] L. Chrétien, G. Arcand, G. Tellier et M. Arcand, Impacts des pratiques de gestion des ressources humaines sur la performance organisationnelle des entreprises de gestion de projets, Revue internationale sur le travail et la société, février 2005

[3] SYSTEMATIC APPROACH TO TRAINING, Experiences from the training activities of regulatory body personnel in STUK, ISBN 951-712-252-7 ISSN 0781-2884 Oy Edita Ab, Helsinki 1997 
[4] Ian Roffe, (1999) "Innovation and creativity in organisations: a review of the implications for training and development", Journal of European Industrial Training, Vol. 23 Iss: 4/5, pp.224 - 241

[5] Belmont, CA, US: Thomson Brooks/Cole Publishing Co Training in organizations: Needs assessment, development, and evaluation, 3rd ed. (1993). xvi 364 pp.

[6] A. MEIGNANT, P.HOURQUET, L.FORGET, « Tous DRH -
Pratique de Gestion des ressources Humaines à l'usage des dirigeants et superviseurs , Editions d'Organisation, 2000

[7] B.Martory, Tableaux de bord sociaux, Editions Liaisons, Paris Cedex, 2010

[8] T. ARDOUIN, Ingénierie de formation pour l'entreprise : analyser, concevoir, réaliser, évaluer, Dunod, Paris, 2010

[9] S.GUERRERO, « Les outils de RH : les savoirs essentiels en GRH », Edition DUNOD, Paris, 2004. 